\title{
Research on the Construction of the AOL of Statistics Course Based on OBE Concept
}

\author{
Shuli Gao, Yanli Guo \\ Business College, Beijing Union University, Beijing, China \\ Email: shuli.gao@buu.edu.cn
}

How to cite this paper: Gao, S. L., \& Guo, Y. L. (2021). Research on the Construction of the AOL of Statistics Course Based on OBE Concept. Open Journal of Social Sciences, 9, 468-475.

https://doi.org/10.4236/jss.2021.92030

Received: December 16, 2020

Accepted: February 23, 2021

Published: February 26, 2021

Copyright (c) 2021 by author(s) and Scientific Research Publishing Inc. This work is licensed under the Creative Commons Attribution International License (CC BY 4.0).

http://creativecommons.org/licenses/by/4.0/ (c) (i) Open Access

\begin{abstract}
This paper aims to build an endogenous assurance of learning (AOL) of statistics course based on OBE concept and AOL framework, which is "outcome-oriented, student-centered and quality continuously improving”. In the concrete construction, it is mainly realized through the following ways: first, the diversified, multi-stage and multi-level training objectives should be determined based on the talent demand survey. Second, individualized and flexible training programs should be inversely designed based on learning objectives. Third, in order to improve the teaching quality, teaching methods need to be innovated continuously. Fourth, internet technology should be utilized to enrich teaching resources. Fifth, a pluralistic, multi-stage and diversified assessment system should be established. At the same time, the training objectives, training programs, assessment and evaluation system should be constantly improved through the feedback mechanism.
\end{abstract}

\section{Keywords \\ OEB Concept, AOL, Construction}

\section{Introduction}

Statistics is a discipline that studies how to effectively collect, sort, and analyze randomized data in order to make inferences or predictions about the problems under investigation, and ultimately provide basis and suggestions for decision-making and action. In the era of knowledge-based economy and digitalization, the development of various fields needs the help of data. Many companies, public service agencies, government departments, etc. hope that their employees have strong data analysis capabilities so that they can dig out gold from the gold mine of big data. In 2019, LinkedIn China released the "Top Startups Rankings" and pointed out that among the 25 companies on the list, nearly half of China's 
startups specialized in artificial intelligence, and among the requirements for employee skills, data analysis skills ranked the first. In the era of big data, everyone needs to master some methods of data analysis. Therefore, in order to meet the market's demand for workers with analytical skills and further improve the quality of teaching and talent training, it is necessary to actively explore the AOL of statistics based on the OBE concept in accordance with the development requirements of the times to enhance students' practical ability and creative thinking of statistics.

\section{Assurance of Learning and $\mathrm{OBE}$ Concept}

The Association to Advance Collegiate School of Business (AACSB) is a world-renowned business accreditation system. Among them, Assurance of Learning (AOL) is one of the important contents of AACSB accreditation. AOL determines the Learning Goals of the degree program according to the mission, further refines the learning goals into quantifiable learning objectives, draws curriculum mapping and builds evaluation criteria based on the learning objectives (Craig et al., 2019). The degree of achievement of students' learning objectives is evaluated and analyzed based on data, and improvement measures are proposed to ultimately promote continuous improvement of teaching. AOL provides an effective teaching quality assurance framework and operating mechanism for business education (Kehal, 2019).

The theoretical basis for building AOL is the OBE concept. Outcomes-based Education (OBE) is an outcome-oriented educational concept, which is based on learning results or outcome-oriented (Zhang, 2019), therefore, we inversely design and continuously adjust students' training goals and teaching model. This teaching model first appeared in the basic education reforms in the United States and Australia, and was subsequently implemented in the United Kingdom, Germany, Japan and other countries and achieved good results. The OBE concept first needs to clarify what goals or results students should achieve in learning; then find and design appropriate and effective methods based on the goals or results, that is, inverse design training programs from the final results, build knowledge and ability modules, and invest in relevant teaching resources to ensure that students can carry out personalized learning and gradually achieve the expected results; finally, evaluate learning results and make continuous improvement. OBE does not have a single method of teaching or evaluation. All courses, practices and assessments should help students achieve the specified output goals or outcomes (Liu, 2018). The final learning results obtained by students are internalized knowledge, experience, skills, professional quality, values, etc., not only refer to professional skills, but also focus on creative thinking ability, analytical ability, and organizing ability, etc., and the maximum ability that can be achieved after one stage of learning. The OBE concept focuses on promoting the transformation of subject-oriented to goal-oriented teaching, teacher-centered to student-centered, and quality control to continuous improvement. 


\section{Construction of AOL for Statistics Course Based on OBE Concept}

Based on the OBE teaching philosophy, when constructing AOL, it is necessary to first clarify the occupational demand of cultivating talents, and develop students' expected learning outcomes based on this; design teaching material and teaching plans and methods according to the expected learning outcomes; and evaluate the students' learning achievements and teaching mode, and make reflections and improvements according to the completion of expected outcomes (Zhong et al., 2020). For statistics, we will propose specific construction ideas from the aspects of teaching objectives, material and methods, assessment system, course resources, feedback and evaluation.

\subsection{Define Teaching Objectives}

In the era of big data, companies, governments and individuals need to use data to make scientific decisions. For example, a large number of decisions are needed in the operation of an enterprise, ranging from the development of the overall development strategy of the enterprise to the replacement and maintenance of spare parts of the production line. These decisions are inseparable from data analysis. Data analysis can help enterprises create greater values and improve efficiency. For example, government departments have a natural advantage in data possession, and they can realize technological, management and model innovation of public services by collecting data and comprehensively processing data. The smart transportation and smart government affairs that are often mentioned at present are inseparable from data analysis. Our daily life is also inseparable from data analysis. Many people wear fitness trackers, such as smart bracelets, to help them know whether their diet is healthy and whether their weight needs to be controlled to stay healthy. This shows that data analysis is widely used in daily life and work. And one of the basic courses for data analysis is statistics. In order to better understand employers' requirements on students' data analysis ability, the course team communicated fully with some enterprises and public institutions and previous graduates before determining talent training and teaching objectives, so as to understand the current employers' demand for graduates' data analysis ability. Many employers favor applied and versatile talents and hope that students have strong self-learning skills, communication skills, basic data analytical skills and report writing skills. In teaching, we focus on students and define the teaching objectives of statistics from the following six dimensions:

Knowledge: Students need to construct the statistical idea of why do we need statistics, what statistics are made, and how to make statistics, and master the basic quantitative analysis methods: descriptive statistics and inferential statistics.

Application: Students can use statistical knowledge and proficiently use relevant statistical software to analyze the collected data and interpret the results correctly. 
Integration: Students can combine the statistical theories and methods they have learned with professional knowledge to solve practical problems in the professional field scientifically and rigorously.

Emotion: Students can actively participate in collaborative learning, have a good team spirit, and communicate effectively with teachers and classmates.

Value: Cultivate students' rigorous and realistic science style, understand the world rationally, understand and abide by professional ethics and norms in practice.

Learning: Students can use various online and offline resources to carry out independent learning and improve their independent learning ability.

\subsection{Restructure Course Content}

Under the premise of clear teaching objectives, the curriculum content design is always student-centered, and adheres to the principle of "emphasis on application and strong ability". On the one hand, it should be designed to focus on cultivating students' ability to apply professional theoretical knowledge to the practical areas; on the other hand, to cultivate students' ability to find, analyze and solve problems; meanwhile, students should be taught to abide by professional ethics and norms (Fan, 2020). Facing the development opportunities and challenges brought by big data to statistics, in the teaching process, teachers should timely catch up with the cutting-edge knowledge and related technologies and theories, supplement and update the teaching content, further stimulate students' enthusiasm for learning, cultivate students' statistical thinking and improve their practical ability. Therefore, the design of teaching content focuses on reconstruction the following:

1) Incorporate commonly used data analysis scenarios of enterprises into the corresponding learning content, and create diversified teaching resources that match the teaching content. The course team provided relevant data analysis cases of different companies, including traditional companies, e-commerce companies, retail companies, etc., and introduced corporate experts into classroom teaching to share real data analysis of companies.

2) Supplement some high-level content to promote the integrative development of education and occupation, which shall be "practical, adequate and easy to use". For example, in the traditional textbook of statistics, the method of data acquisition is non-specific. The acquisition of data on the Internet is only a brief mention, therefore, the content of corresponding data crawling will be added in the teaching process, and students will try to use Cuttlefish software and other tools to obtain network data for analysis. In the chapter of data chart display, in addition to explaining how to use Excel and SPSS to make conventional charts, related visual tools such as Tableau software, online mapping websites, etc. are added to expand students' horizons. Regression analysis is one of the classic analysis methods in statistics. On the basis of explaining unary and multiple linear regression, methods such as dummy variable regression, logistic regression, 
and curve regression are added.

3) Strengthen students' ability to use statistical software and the ability to write statistical reports. Statistical techniques are quite mature and systematic for collecting and analyzing data in the traditional sense, but when the amount of data is large, especially when it contains a lot of unstructured data, statistical techniques are far from enough. The computing problem is a question of questions. Due to a large amount of data, the calculated amount is large. This requires us to closely integrate traditional statistical techniques with modern information technology. Currently, for undergraduates not majoring in statistics, they mainly study SPSS. With the implementation of the new major cultivation program, software such as $\mathrm{R}$ and Python will be used in the future courses to achieve efficient data processing and analysis. If you only learn the operation of the data analysis software, it is not enough. An analyst needs to be able to analyze and interpret the data uniquely, to see earlier, wider, and deeper than others, and to make valuable suggestions. This requires training in the writing of students' analysis reports.

\subsection{Innovate Teaching Methods}

Based on the OBE educational philosophy, the curriculum is designed into different modules, and the SPOC and flipped classroom hybrid learning mode of statistics teaching are actively explored. The learning effect is improved by integrating online and offline teaching. The students' active learning and in-depth learning should be achieved by improving their active learning experience. A community for growth of both teachers and students should be built to further improve the quality of talent training.

Before class, teachers place teaching courseware, micro lecture videos, curriculum resources, course learning objectives and requirements on the network platform, allowing students to preview and complete related tests in advance. Before flipping the classroom, the teachers must reconstruct the class content, namely, what content can be explained in detail and what content does not need to be explained, and the content not to be explained means that students can learn and master it through online videos for many times, while the content to be explained is the part where students have more questions in the pre-class test and the knowledge points are difficult to understand. What kind of teaching method is adopted in class is a question that needs to be considered in advance. The content in the class is not to repeat the content in the online video, otherwise it will be meaningless. For example, when explaining parameter estimation, students can understand theoretical knowledge by asking questions and sorting out knowledge, and then understand how to apply theoretical knowledge into practice by introducing cases, group discussions and course experiments. According to the difficulty of the content of the course modules, various forms such as reporting and lectures can also be used to allow students to play a dominant role in teaching and complete the learning tasks through reflection, discus- 
sion, answering questions, and searching information. Of course, in this process, the corresponding evaluation should be conducted to avoid the phenomenon of students' hitchhiking. Finally, students can go back online to complete after-class exercises and homework. Homework should be completed at the prescribed time, which is not only conducive to further consolidating students' knowledge, but also enables teachers to keep track of students' learning status at any time. In addition, the teaching should not be limited to the classroom, but should be extended to after class. After mastering the relevant knowledge of data analysis, teachers should encourage students to participate in relevant academic competitions, such as market research competitions, star competitions, entrepreneurship competitions, etc., so as to enhance their practical ability and teamwork ability.

\subsection{Enrich Teaching Resources}

With the development of information technology and Internet education, many online teaching platforms or APPs have emerged. Course teachers can publish course-related courseware, learning materials, videos, exercises, etc. on some platforms or APPs, and set up discussion sections; they can also link to domestic and foreign learning resources to show some learning materials that cannot be displayed in classrooms due to conditions and time, guide students to strengthen the learning and understanding of in-class knowledge outside the classroom. Teachers can also use WeChat groups, official accounts, etc., to establish a link between students' in-class and extra-curricular learning, answer students' questions in a timely manner, initiate discussions, introduce cutting-edge knowledge of data analysis, etc. to guide students' extracurricular learning. While promoting students' inquiry-based learning and independent learning, students' vision is constantly broadened and their thinking of data analysis is constructed.

\subsection{Multi-Dimensional Assessment}

Based on the OBE concept, a variety of assessments and evaluations of students' learning achievements are carried out throughout the learning stage, especially the diversified process evaluation is conducive to strengthening students' understanding of knowledge and practical application capabilities. Through process evaluation, teachers can understand the actual learning conditions of students at any time, and then evaluate the effect of classroom teaching in order to adjust the teaching methods and content in time. In the process assessment, students' attendance, pre-class preview, classroom participation, and learning outcomes, etc. can be assessed, and students' completion status (group task completion status, individual task completion status), and project results, etc. should also be evaluated (Isabella et al. 2017). For specific implementation, relevant teaching platforms can be used, such as MOOC, cloud classes, etc., to grasp the student's learning progress, content and effect, etc. in real time, and provide personalized guidance in time. The multi-dimensional assessment system should also include 
the evaluation of teachers. According to the accomplishment of students' expected results and goals, teachers should reflect on whether there are deviations between the plan and the actual results in each teaching link in the early stage, and continuously optimize the talent training model and curriculum design to form "closed loops".

\section{Conclusion}

The paper discusses how to build the assurance of learning system of statistics based on OBE concept, aiming to take the output of students' learning outcomes as the utmost goal, and designing an online and offline teaching mode suitable for statistics course learning based on the actual curriculum goals. Through the application-oriented reforms of course objectives, course content, teaching methods, course resources, assessment and evaluation, etc., the status quo of passive learning of students in traditional courses will be changed, the close combination of the theoretical part and the practical part of the course will be strengthened and the effectiveness of students' learning will be improved. Of course, the construction of assurance of learning is inseparable from the implementation of all kinds of safeguard measures, including the attention of leaders at all levels of the college, the understanding and cooperation of teachers in the curriculum team, the matching of corresponding personnel and resources, the establishment and improvement of standards and systems, etc., so as to finally form an educational cultural atmosphere with "continuous improvement" and "goal orientation" as the core. The advancement and effectiveness of the OBE concept teaching model will contribute to the in-depth reform of the teaching of the statistics course, and will definitely help to effectively improve the learning outcomes of students and enhance their professional skills to meet the ever-changing market needs.

\section{Acknowledgements}

The authors are grateful for the financial support provided by the Premium Funding Project for Academic Human Resources Development in Beijing Union University (BPHR2017CS06) and Key Issues of Teaching Reform (JJ2020Z002).

\section{Conflicts of Interest}

The authors declare no conflicts of interest regarding the publication of this paper.

\section{References}

Craig, H., Candice, L. C., \& Timothy, J. W. (2019). Creating a Research Culture on the Way to AACSB Accreditation. Journal of Education for Business, 3, 204-208. https://doi.org/10.1080/08832323.2018.1510362

Fan, Y. J. (2020). Exploration of Personnel Training Mode of Statistics Major in Local Financial and Economic Colleges Based on OBE. Higher Education Forum, 7, 9-11. 
Isabella, D., Melanie, A. R., \& Thomas, J. T. (2017). A Focus on Engagement: Defining, Measuring, and Nurturing a Key Pillar of AACSB Standards. Organization Management Journal, 4, 45-55. https://doi.org/10.1080/15416518.2017.1293427

Kehal, M. (2019). Assurance of Learning and Accreditations in Business Schools: An AACSB Perspective. Journal of Economic and Administrative Sciences, 36, 82-96. https://doi.org/10.1108/JEAS-06-2018-0066

Liu, X. Y. (2018). Establishment and Operation of AOL System Based on AACSB Certification. Accounting communication, 25, 39-41.

Zhang, N. X. (2019). Promoting the Quality of Professional Education in Colleges Based on OBE. University Education Science, 2, 11-13.

Zhong, W. B., Wang, M. X., \& He, Q. (2020). Improvement of Course Teaching Based on the AOL Standards of AACSB: A Case Study of the Course "Financial Management". Journal of University of Shanghai for Science and Technology, 3, 91-95. 